\title{
PENERAPAN BAHASA JURNALISTIK DALAM PENULISAN NASKAH SIARAN BERITA PADA KARYA PRAKTIKUM JURNALISTIK TELEVISI
}

\author{
Hariyanto $^{1}$, Joko Suryono ${ }^{2}$, Dewi Kusumaningsih ${ }^{3}$ \\ ${ }^{1,2}$ Program Studi Ilmu Komunikasi, Universitas Veteran Bangun \\ Nusantara \\ ${ }^{3}$ Program Pendidikan Bahasa Indonesia, Universitas Veteran Bangun \\ Nusantara
}

Author Correspondence : abdulhamidhariyantowidodo@gmail.com

\begin{abstract}
Abstrak
Kegiatan praktikum jurnalistik televisi oleh mahasiswa perlu diarahkan untuk dapat dilakukan semaksimal mungkin menuju jurnalis televisi standar profesional. Oleh karena itu, perlunya ketrampilan penggunaan bahasa Indonesia yang tepat khususnya pada penerapan bahasa jurnalistik dalam penulisan naskah siaran berita untuk menghasilkan karya jurnalistik televisi yang layak ditonton. Penelitian ini bertujuan untuk mengetahui bagaimana penerapan bahasa jurnalistik dan proses editing dalam penulisan naskah siaran berita oleh mahasiswa pada karya praktikum jurnalistik televisi. Metode penelitian yang digunakan adalah deskriptif kualitatif. Pengumpulan data dengan pengamatan terhadap transkrip dari dokumen video hasil karya praktikum jurnalistik mahasiswa yang ada pada univet televisi youtube channel dengan judul berita Univet Tv - Makrab I.Kom Fisip Univet Bantara Sukoharjo dari laman https://www.youtube.com/watch?v=601Y804vfj4 Analisis dilakukan dengan cara menentukan kriteria dari naskah-naskah berita televisi yang mengandung 5 unsur bahasa jurnalistik yaitu; ketepatan (accuracy), kepadatan (brevity), kejelasan (clarity), kesederhanaan (simplicity), dan dapat dipercaya (sincerity). Hasil penelitian menunjukkan bahwa, penulisan naskah siaran berita televisi karya praktikum jurnalistik televisi oleh mahasiswa belum sepenuhnya menerapkan penggunaan bahasa indonesia yang baik sesuai dengan kaidah bahasa jurnalistik televisi yang memenuhi 5 kriteria unsur bahasa jurnalistik, baik itu dari pemilihan kata maupun penempatan kata dalam struktur kalimat. Sedangkan, dari sisi pengeditan naskah berita, belum ada tim khusus atau seseorang yang bertanggung jawab penuh dalam mengedit naskah berita televisi sebelum ditayangkan.

Kata kunci: bahasa, jurnalistik, televisi, praktikum, mahasiswa
\end{abstract}

\section{Abstract}

Television journalism practicum activities by students need to be directed to be carried out as closely as possible towards professional standard television journalists. Therefore, the need for appropriate Indonesian language skills especially in the application of journalistic language in writing news broadcast scripts to produce television journalism that is worth watching. This study aims to determine how the application of journalistic language and the editing process in writing news broadcast scripts by students on television journalistic practical work. The research method used is descriptive qualitative. Collecting data by observing transcripts from video documents of student journalism practicum work on the youtube channel television station with the title Univet Tv-Makrab I. Kom FisipUnivet Bantara Sukoharjo from the https://www.youtube.com/watch? $v=601 Y 804 v f j 4$ Analysis is done by determining the criteria of television news manuscripts containing 5 elements of journalistic language, namely; accuracy, density (brevity), clarity, simplicity, and can be trusted (sincerity). The results showed that, the writing of television news broadcast manuscripts by television journalism practicum by students has not fully implemented the use of Indonesian language that is in accordance with the rules of television journalism language that meets the 5 criteria of journalistic language elements, both from the choice of words and placement of words in sentence structure. Meanwhile, in terms of editing the news script, there is no special team or someone who is fully responsible for editing the television news script before it is aired.

Keywords: language, journalism, television, practicum, students 


\section{PENDAHULUAN}

Program Studi Ilmu Komunikasi Fakultas Ilmu Sosial dan Ilmu Politik Universitas Veteran Bangun Nusantara Sukoharjo menyelenggarakan pendidikan tinggi tingkat sarjana strata satu (S1) dengan konsentrasi jurnalistik. Mata kuliah praktikum jurnalistik televisi merupakan salah satu mata kuliah yang ada dalam kurikulum. Mata kuliah ini merupakan mata kuliah ketrampilan jurnalistik yang pelaksanaananya dilakukan dengan cara praktik. Mahasiswa peserta mata kuliah ini dibagi dalam beberapa kelompok tim liputan. Sebuah tim liputan untuk praktikum jurnalistik televisi biasanya terdiri dari 5-6 orang mahasiswa. Sebelum kegiatan praktikum jurnalistik televisi dilakukan, dosen pengampu mata kuliah praktikum akan memberikan petunjuk-petunjuk praktikum dan prosedur liputan yang sesuai dengan kaidah jurnalistik khususnya televisi. Bersama laboran, dosen praktikum akan menyiapkan perlengkapan dan peralatan yang dibutuhkan oleh tim liputan yang diberi tugas meliput berita.

Sebagai langkah awal, dosen praktikum menayangkan video contoh karya-karya jurnalistik televisi standar profesional yang dihasilkan oleh para jurnalis dalam televisi nasional yang didownload dari https://www.youtube.com/. Hal ini dilakukan untuk memberi gambaran awal dan pemahaman kepada tim liputan, bagaimana seharusnya bekerja bersama dengan tim masing-masing agar dapat menghasilkan karya jurnalistik televisi yang layak untuk ditonton. Selain itu, tayangan video contoh tersebut juga dapat menjadi rujukan bagaimana cara menyusun naskah berita televisi standar profesional mulai dari opening atau intro news, body news, soundbite dan closing news.

Capaian pembelajaran dari mata kuliah praktikum jurnalistik televisi adalah mahasiswa mampu menghasilkan karya jurnalistik televisi yang layak ditonton dan itu harus dilakukan dalam kerjasama bersama tim liputan yang telah dibentuk oleh pengampu praktikum. Mahasiswa akan berperan menjadi kameramen, reporter, news reader/presenter/anchor, script writer dan redaktur liputan. Pengampu praktikum memberikan beban tugas kepada tim liputan jurnalistik televisi untuk menghasilkan beberapa karya jurnalistik televisi berupa paket berita televisi lengkap yang terdiri dari gambar suasana di tempat liputan, narasi voice over, rekaman wawancara dengan narasumber dan reportase dari tempat liputan. Hasil liputan harus di-editing sedemikian rupa sehingga memenuhi struktur berita televisi yang terdiri dari opening television, pembacaan teras berita/intro news, badan berita/body news dan penutup berita/closing news. Video berita hasil karya praktikum jurnalistik televisi wajib untuk dipublikasikan lewat https://www.youtube.com/. Dosen pengampu praktikum memberikan deadline waktu maksimal 3 minggu untuk masing-masing kelompok tim liputan untuk menghasilkan karya jurnalistik televisi yang sudah harus ter-upload di https://www.youtube.com/. Untuk setiap kelompok liputan yang sudah berhasil upload karyanya akan mendapat nilai sesuai dengan syarat dan ketentuannya. Setiap kelompok tim liputan yang mampu memenuhi standard kelayakan berita televisi akan mendapatkan nilai paling baik.

\section{Bahasa Jurnalistik Televisi}

Bahasa ialah alat komunikasi yang terorganisasi dalam bentuk satuan-satuan, seperti kata, kelompok kata, klausa, dan kalimat yang diungkapkan baik secara lisan maupun 
tulis. Bahasa merupakan sistem komunikasi manusia yang dinyatakan melalui susunan suara atau ungkapan tulis yang terstruktur untuk membentuk satuan yang lebih besar, seperti morfem, kata, dan kalimat. (Wiratno \& Santosa, 2014, p. 1). Bahasa juga merupakan sarana untuk berkomunikasi antara sesama sebagai anggota masyarakat bahasa (language community). Bahasa mencakup beberapa unit ketatabahasaan yang meliputi antara lain; sintaksis, semantik, dan fonologi yang merupakan unsur dasar dalam kegiatan berbahasa. Element-element ini memiliki peran yang sangat penting dalam proses berfikir manusia serta pengungkapan hasil pemikirannya itu dalam bentuk bahasa, baik bahasa lisan maupun bahasa tulisan (Mahmudi, 2016, p. 1).

Bahasa jurnalistik atau seringkali disebut juga dengan bahasa pers, merupakan salah satu dari ragam bahasa kreatif bagian dari bahasa Indonesia. Bahasa jurnalistik ini di samping sebagai bahasa pers/bahasa media di dalamnya juga memuat pula ragam bahasa akademik (ilmiah), ragam bahasa literer (sastra), ragam bahasa filosofik, dan ragam bahasa usaha (bisnis).

Bahasa jurnalistik bagian dari laras atau ragam dalam bahasa Indonesia. Meskipun bahasa jurnalistik memiliki sejumlah kekhususan, namun demikian bahasa jurnalistik merupakan bahasa Indonesia yang baku, yang artinya harus memperhatikan kaidahkaidah yang berlaku. Dengan demikian, bahwa bahasa jurnalistik Indonesia tetap bahasa Indonesia yang baku, yang baik, dan yang benar. Posisi bahasa jurnalistik, berada di tengah-tengan antara bahasa ilmu dan bahasa sastra. Bahasa ilmu adalah bahasa yang penuh dengan fakta, kering dan bahkan tidak bergaya, sementara bahasa sastra adalah bahasa yang penuh dengan imaginatif dan juga penuh dengan gaya. Penerapan bahasa jurnalistik tetaplah harus berdasarkan pada fakta-fakta, namun demikian harus tetap ada gayanya pula. Bahasa jurnalistik ditulis dengan mempertimbangkan ruang dan waktu, karena itu unsur kehematan dan efektifitas sangat penting. Tidak mungkin jurnalis menulis untuk media massa semaunya tanpa memperhitungkan ruang dan waktu yang tersedia (deadline). Selain ruang dan waktu, bahasa jurnalistik juga perlu mempertimbangkan target khalayak yang menjadi sasarannya.

Bahasa jurnalistik televisi merupakan bahasa yang digunakan oleh para jurnalis berita televisi dalam menyampaikan informasi atau berita khususnya di media massa televisi. Para jurnalis media televisi dalam menyajikan berita televisi wajib menggunakan bahasa jurnalistik televisi sesuai dengan karakteristik media televisi tempat mereka bekerja. Para jurnalis televisi di Indonesia tentunya wajib menggunakan bahasa Indonesia sebagai bahasa jurnalistiknya (Usman, 2009, p. 24). Dalam praktiknya penggunaan bahasa Indonesia dalam ragam jurnalistik secara umum masih belum sesuai dengan kaidah bahasa Indonesia yang baik dan benar. Hal ini karena masih kurangnya pengetahuan mengenai pemakaian standar Ejaan Yang Disempurnakan (EYD) dan tata tulis yang sesuai dengan kaidah bahasa Indonesia (Baksin, 2006, p. 69). Maka dari itu menerapkan prinsip-prinsip tersebut tentunya diperlukan latihan berbahasa tulis secara terus menerus, serta melakukan penyuntingan tanpa pernah berhenti. Dengan demikian keinginan jurnalis televisi untuk menyajikan ragam bahasa jurnalis yang sesuai dengan kaidah bahasa Indonesia yang telah ditetapkan mudah dimengerti oleh masyarakat serta memuaskan para pemirsanya akan bisa diwujudkan.

Jenis bahasa jurnalistik televisi berbeda dengan bahasa tulis pada umumnya karena bahasa jurnalistik televisi memiliki sifat intimacy (kedekatan/intim). Pada umumnya bahasa jurnalistik yang digunakan untuk menyusun naskah berita televisi adalah bahasa informal yang berupa bahasa tutur. Bahasa tutur inilah yang memungkinkan terjadinya kontak antara pembaca berita/news anchor dengan pemirsanya/audience. Pada saat 
seseorang menyaksikan tayangan berita televisi seolah-oleh terjadi kontak mata antara pembaca berita/news anchor dan reporter dengan pemirsa. Dengan demikian maka proses komunikasi dalam penyiaran dapat berjalan lancar dan berhasil guna yakni pesan/informasi yang disampaikan akan dapat diterima oleh pemirsa (Baksin, 2006, p. 70).

Pengaruh arus globalisasi dalam identitas bangsa tercermin pada perilaku masyarakat yang mulai meninggalkan bahasa Indonesia dan terbiasa menggunakan bahasa gaul. Saat ini jelas di masyarakat sudah banyak adanya penggunaan bahasa gaul dan hal ini diperparah lagi dengan generasi muda Indonesia juga tidak terlepas dari pemakaian bahasa gaul. Bahkan, generasi muda inilah yang paling banyak menggunakan dan menciptakan bahasa gaul di masyarakat. Fenomena lainnya adalah bahasa alay yang kerap digunakan dalam media sosial maupun percakapan sehari-hari. Pergeseran struktur kata yang terjadi di masa sekarang dan dilakukan oleh banyak kalangan membentuk munculnya kosakata baru yang meminggirkan keformalan dalam berbahasa.(Rahayu, 2015, p. 1)

Menurut Morrisan bagi banyak orang televisi adalah teman, televisi merupakan cermin perilaku masyarakat dan dapat menjadi candu. Televisi dapat membujuk kita untuk mengkomsumsi lebih banyak dan lebih banyak lagi. Ringkasnya televisi mampu memasuki relung-relung kehidupan kita lebih dari yang lain. (Morissan, 2005, p. 3)

Media televisi menyiarkan suara sekaligus menyiarkan gambar atau bersifat audiovisual dan sinematografik (pandang dengar dan gambar bergerak). Pada media televisi, antara suara dan gambar yang muncul haruslah sesuai atau sejalan (sinkron) merupakan hal yang mutlak. Berita sudah menjadi bagian penting dalam program stasiun televisi.

Ditegaskan oleh Muda bahwa khusus untuk televisi, informasi yang diperoleh melalui televisi dapat mengendap lama dalam daya ingatan manusia dibanding informasi melalui

bacaan (Muda, 2003). Hal tersebut diperkuat dengan membutuhkan teknik penulisan yang tepat dan sederhana daripada media cetak agar mudah dipahami dan ditangkap oleh daya ingat manusia pada setiap penayangan berita dari stasiun penyiaran melalui televisi. Adanya gambar atau visual sangat membantu pekerjaan reporter ketika menulis naskah

berita, karena karya visual akan mampu memecahkan masalah. Menurut Gunawan,

Sachari dalam (Suryono, Astuti, Rahayu, Hariyanto, \& Widayati, 2019) karya visual adalah wujud kasat mata dari aspek sosial, ekonomi dan tata hidup manusia sebagai ungkapan kehidupan manusia yang tidak dibatasi oleh letak geografis dan mampu memecahkan permasalahan. Reporter televisi tidak perlu menjelaskan segala sesuatunya dengan terlalu rinci karena sebagian besar fakta telah dijelaskan dengan gambar. Karena itu penting bagi reporter televisi untuk menghindari pembenahan naskah yang terlalu panjang atau bahasa yang rumit.

\section{Penulisan Naskah Siaran Berita Televisi}

Setiap jurnalis tentunya mempunyai ciri khas masing-masing, begitu pula gaya penulisan dalam menulis atau melaporkan berita. Setiap reporter televisi tentunya berbeda-beda juga dalam menulis naskah berita televisi yang akan dipublikasikan melalui media televisinya, singkat kata, lain reporter lain pula gayanya. Usman KS merangkum karakteristik-karakteristik bahasa jurnalistik televisi antara lain: pertama, menggunakan bahasa sehari-hari dengan gaya bahasa percakapan dan menggunakan kalimat tutur (bercerita). Kedua, menggunkan kata dan atau kalimat sederhana dengan menghindari kata-kata asing, kata klise, istilah teknis dan eufimisme. Ketiga, menggunakan kalimat 
pendek dengan prinsip ekonomi kata. Keempat, menghindari kalimat terbalik, subjek dan predikat berdekatan posisinya, jabatan mendahului pemangku jabatan. Kelima, menggunkan kalimat aktif, jangan menyembunyikan kata kerja kuat dibalik kata benda. Keenam, jangan terlapau banyak menggunakan angka-angka. (Usman, 2009, pp. 26-29)

Selain itu, perbedaan dari sifat, karakter, dan ideologi yang dianut oleh media juga turut mempengaruhi, sehingga tidak mungkin sama dan diseragamkan. Tetapi dalam hal penyajian berita di media elektronik, ada prinsip umum yang harus diperhatikan oleh semua Jurnalis atau reporter. Menurut Zaenuddin, sedikitnya ada 17 prinsip yang harus diperhatikan yaitu : masuk akal, jelas, hemat dan ekonomis, konsisten dan argumentatif, seimbang, narasumber punya otoritas, patuhi azas praduga tak bersalah, memperhatikan rumus $5 \mathrm{~W}+1 \mathrm{H}$, hindari kata-kata subjektif, enggel harus jelas, lead menarik, mudah dimengerti, mengandung informasi baru, struktur harus rapi dan sistematis, cermat dan akurat, pakai istilah yang tepat dan yang terakhir jangan bohong (Zaenuddin, 2007, p. 191)

Dalam penulisan berita aktual dapat disajikan dalam dua bentuk yaitu:Pertama, berita langsung (straight news) untuk berita kuat (hard/spot/soft news) yaitu uraian fakta dan atau pendapat yang hanya mengandung $5 \mathrm{~W}+1 \mathrm{H}$, dan uraiannya dimulai dari yang terpenting menuju ke yang kurang penting. Fakta dan atau pendapat yang dilaporkan itu hanya terlihat dari satu sudut atau aspek sehingga bersifat linier. Kedua, berita mendalam (indepth news) yaitu uraian fakta dan atau pendapat yang mengandung nilai berita, dengan menempatkan fakta dan atau pendapat itu pada mata rantai dan merefleksikannya dalam konteks permasalahan yang lebih luas. Fakta dan atau pendapat itu dilihat dari banyak sudut atau aspek sehingga bersifat multilinier. Naskah berita televisi terdiri atas tiga bagian, yaitu : 1) intro berita/lead news, 2) badan berita (body news, 3) penutup berita (ending news), 4) soundbite

Pertama, intro berita atau lead news merupakan bagian terpenting dari suatu berita. Berita televisi selalu dimulai dengan intro yang dibacakan oleh penyiar di studio. Intro merupakan rangkuman dari seluruh unsur terpenting dari suatu berita dengan latar belakang dan konteks yang diperlukan. Intro sebisa mungkin harus mengandung hampir seluruh unsur terpenting suatu berita yang mencangkup rumus $5 \mathrm{~W}+1 \mathrm{H}$, yaitu, what, where, when, why, dan who, sedangkan pada badan berita berfungsi untuk menguraikan unsur how yang belum dijelaskan pada intro. Jadi intro adalah tulang punggung dari suatu berita. Dengan demikian fungsi utama intro adalah untuk menjual berita tersebut kepada pemirsa. Intro berfungsi untuk menarik perhatian penonton agar menyimak berita bersangkutan sampai akhir.

Kedua, badan berita atau body news. Pekerjaan selanjutnya adalah menulis badan berita atau badan narasi. Ketika menulis badan berita, maka stuktur penceritaan berita tidak boleh loncat-loncat atau bolak-balik. Setiap perkembangan fakta atau informasi harus disesuaikan dengan alurnya, baru setelah itu pindah ke perkembangan selanjutnya. Narasi harus diselaraskan dengan gambar agar tidak membingungkan pemirsa, karena itu sebelum menulis naskah berita lihat dulu videonya. Tentukan Soundbite/SOT dan gambar yang akan digunakan, termasuk juga natsound-nya, setelah itu menulislah berdasarkan gambar. Fungsi narasi dalam berita televisi bukan untuk menceritakan gambar, tetapi untuk melengkapi atau mendukung gambar, karena itu narasi tidak perlu panjang. Reporter harus berani diam jika gambar sudah bercerita sendiri (reporter must dare to be silent, if the picture speaks for itself).

Ketiga, penutup berita (ending news). Segera akhiri naskah berita bila tidak ada lagi fakta atau info yang relevan atau signifikan yang perlu diceritakan atau bila panjang 
naskah sudah mencapai akhir alokasi waktunya. Walaupun terletak pada bagian buntut, namun reporter tidak boleh mengabaikan bagian penutup. Dalam membuat ending ini, reporter atau penulis narasi harus mengacu kembali kepada intro berita atau lead news yang sudah lebih dulu dibuat. Penutup harus terkait dengan awal cerita guna menjaga keutuhan atau kebulatan cerita dan tetap pada benang merahnya.

Keempat, Soundbite. Kutipan atau ucapan langsung narasumber atau soundbite (SOT) merupakan bagian yang penting dari suatu berita. Berita akan menjadi lebih kuat bila ada SOT, namun SOT harus dibatasi pada pernyataan atau bagian pernyataan yang benar-benar relevan yang diperlukan bagi penjelasan informasi yang memperkuat berita itu.

\section{METODE PENELITIAN}

Metode penelitian yang digunakan adalah deskriptif kualitatif dengan fokus pengamatan terhadap transkrip dokumen video hasil karya praktikum jurnalistik mahasiswa yang ada pada univet televisi channel di https://www.voutube.com/watch?v=601Y804vfi4 Menurut Moleong, fokus pengamatan ini dilakukan untuk mengarahkan pelaksanaan pengamatan.(Moleong, 2017, p. 179). Objek pengamatan dalam penelitian kualitatif yaitu situasi sosial yang terdiri dari tiga komponen yakni tempat, pelaku, aktivitas. Dari tiga komponen tersebut dapat diperluas sehingga pengamatan dapat dilakukan seperti terhadap; ruang dalam aspek fisik, semua orang yang terlibat dalam situasi sosial, seperangkat kegiatan yang dilakukan orang, benda-benda yang terdapat di tempat itu, perbuatan atau tindakan tertentu, rangkaian terhadap aktivitas yang dikerjakan orang-orang, urutan kegiatan, tujuan yang ingin dicapai orang-orang, dan emosi yang dirasakan dan diekspresikan oleh orang-orang (Sugiyono, 2017, pp. 110-111).

Analisis naskah dokumen dilakukan dengan cara menyimak. Teknik simak, pemaknaan, dan catat menurut Santosa, Subroto, Sudaryanto dalam (J Suryono , P I Astuti, N T Rahayu, 2019) semua frame gambar dilakukan penyimakan, pemaknaan dan pencatatan dengan menentukan kriteria dari naskah-naskah berita televisi yang mengandung bahasa jurnalistik dan fokus pengamatan pada urutan kegiatan yang tertulis dalam naskah berita televisi dengan memenuhi 5 unsur bahasa jurnalistik seperti; ketepatan (accuracy), kepadatan (brevity), kejelasan (clarty), kesederhanaan (simplicity), dan dapat dipercaya (sincerity) (Badjuri, 2010, pp. 63-67). Hasil transkrip dokumen video hasil karya praktikum jurnalistik mahasiswa yang ada pada univet televisi channel di https://www.voutube.com/watch?v=601Y804vfj4 akan dianalisis menggunakan 5 kriteria tersebut.

\section{HASIL DAN PEMBAHASAN}

\section{Naskah Berita Televisi}

Naskah berita televisi tidak harus banyak penjelasannya karena penjelasan yang utama telah ditunjang oleh gambar rekaman peristiwa yang diliput, maka kemudian dibutuhkan bahasa jurnalistik yang komunikatif dan tepat agar penonton dapat memahami secara cepat. Menulis naskah berita televisi adalah menulis untuk didengar. Karena televisi merupakan media audio-visual maka pemirsa atau penonton akan melihat gambar dan teks sebagai visual sekaligus akan mendengar suara sebagai audio (Badjuri, 
2010, p. 25). Pola ideal dalam penyusunan naskah berita televisi setidaknya terdapat cerita lima kalimat (a five sentence news story) sebagai berikut yakni; pertama, inti berita (lead news), kedua, detail yang penting, ketiga latar belakang peristiwa, keempat, detail lain dan kelima, interpretasi peristiwa. Penyusunan naskah berita televisi berpola piramida terbalik yaitu; mulai dari apa inti dari berita-nya, kemudian setting kejadian, apa kejadiannya, siapa pelakunya, di mana kejadiannya, kapan kejadiannya. Selanjutnya ditambahkan elemen-elemen pelengkap berdasarkan fakta peristiwa. Selain itu dapat menambhkan peristiwa pembanding sehingga dapat melihat perbedaannya dengan peristiwa sejenis. ((Badjuri, 2010, p. 30)

Penelitian ini fokus menganalisis isi naskah berita televisi yang sengaja dipilih dari hasil karya praktikum jurnalistik televisi oleh mahasiswa yang erat kaitannya dengan penerapan bahasa indonesia dalam penyusunan naskah berita televisi. Bahasa jurnalistik televisi yang sesuai dengan kaidah adalah bahasa jurnalistik yang memenuhi kriteria 5 unsur yaitu ketepatan (accuracy), kepadatan (brevity), kejelasan (clarty), kesederhanaan (simplicity), dan dapat dipercaya (sincerity)(Badjuri, 2010, pp. 63-67).

\section{Ketepatan (Accuracy)}

Penulisan berita harus tepat sesuai dengan fakta peristiwa/kejadiannya. Data yang dituliskan harus sesuai dengan konteks permasalahan yang diliput dan dapat dipertanggungjawabkan secara moral dan hukum. Nama orang, jabatan orang, tempat kejadian, tanggal kejadian, dan data-data yang berkaitan dengan angka tidak boleh melenceng. Berita yang ditulis adalah fakta dari peristiwa yang sebenarnya. Tidak boleh mengandung opini atau pendapat dari jurnalis. Kalau tulisan mengandung opini, berita akan cenderung tidak sesuai dengan konteks permasalahan.

Berikut di bawah ini kutipan dari naskah-naskah berita hasil karya praktikum jurnalistik televisi dari https://www.voutube.com/watch?v=601Y804vfi4 yang diambil dari univet televisi channel yang menunjukkan ketepatan naskah berita yang berjudul : Makrab Mahasiswa Ilmu Komunikasi FISIP 2018.

OPENING TELEVISI

SELAMAT PAGI PEMIRSA/ ANDA SEDANG MENYAKSIKAN UNIVET

TV/ 21 OKTOBER 2018/ BERSAMA SAYA/ FIRDA//

\section{LEAD NEWS}

UNIVERSITAS VETERAN BANGUN NUSANTARA SUKOHARJO/

FAKULTAS ILMU SOSIAL POLITIK /MENGADAKAN ACARA

MAKRAB YANG BERTEMPATKAN DI TAWANGMANGU//

ACARA MAKRAB TERSEBUT DIIKUTI OLEH MAHASISWA PROGDI

ILMU KOMUNIKASI TAHUN ANGKATAN 2018// BERIKUT LIPUTANNYA//

\section{BODY NEWS:}

PEMBUKAAN MAKRAB FISIP DILAKSANAKAN PADA HARI JUMAT/

28 SEPTEMBER 2018/ DI GEDUNG D LANTAI 2/ DAN DIBUKA PUKUL 7 WAKTU INDONESIA BARAT OLEH DEKAN FISIP/ DRS. JOKO

SURYONO, M.SI.//

ACARA TERSEBUT BERLANGSUNG 3 HARI 2 MALAM/ DI VILLA

FAJAR INDAH TAWANGMANGU KANGANGANYAR// 

ADA BANYAK KEGIATAN YANG DILAKSANAKAN//
KEGIATAN HARI PERTAMA/ MENGENALKAN FAKULTAS ILMU
SOSIAL DAN ILMU POLITIK/ PRODI ILMU KOMUNIKASI
UNIVERSITAS VETERAN BANGUN NUSANTARA
SUKOHARJO/KEMUDIAN HARI KEDUA DILAKSANAKANYA
KEGIATAN SENAM/OUT BON DAN MALAM HARINYA INAGURASI//
PADA HARI TERAKHIR MAKRAB DISI JALAN SEHAT DAN
KALERAN///

\section{CLOSSING:}

INFORMASI TERSEBUT MENGAKHIRI PERJUMPAAN KITA PADA

PAGI HARI INI/SAYA /FIRDA/PAMIT UNDUR DIRI/SELAMAT

BERAKTIFITAS DAN SAMPAI JUMPA///

Dari kutipan di atas, terdapat ketepatan terletak masing-masing unsur yakni: (1) nama subjek terdapat pada kalimat DRS. JOKO SURYONO, M.SI (2) keterangan subjek pada kalimat, DEKAN FISIP (3) keterangan kondisi tertulis pada kalimat PEMBUKAAN MAKRAB FISIP DILAKSANAKAN PADA HARI JUMAT/ 28 SEPTEMBER 2018 DIBUKA PUKUL 7 WAKTU INDONESIA BARAT dan pada kalimat ACARA TERSEBUT BERLANGSUNG 3 HARI 2 MALAM (4) keterangan tempat yaitu pada DI GEDUNG D LANTAI 2. Dan tempat yang lain yaitu pada kalimat VILLA FAJAR INDAH TAWANGMANGU KANGANGANYAR (5) keterangan objek yaitu pada kalimat DIIKUTI OLEH MAHASISWA PROGDI ILMU KOMUNIKASI TAHUN ANGKATAN 2018.

Perpaduan unsur ketepatan naskah di atas, pemirsa dapat dengan mudah memahami isi pemberitaan. Unsur bahasa jurnalistik televisi yang baik dan perlu dipertahankan dalam pemberitaan sejenis yakni pencantuman nama subjek sumber berita setelah nama jabatan. Ketepatan ini memberikan peluang lebih besar bagi pemirsa untuk mengetahui secara tepat dan akurat tentang subjek pemberitaan.

Naskah berita televisi di atas secara isi teks telah memenuhi unsur ketepatan (accuracy), namun dalam penyusunan kalimat yang memenuhi kaidah bahasa jurnalistik terutama yang berkaitan dengan kalimat-kalimat pemberitaan. Pertama, kalimat pada intro berita (lead news). Susunan kalimat yang terdapat pada intro berita menunjukkan bahwa naskah intro berita tersebut belum dapat memenuhi seluruh unsur terpenting suatu berita yang mencangkup rumus $5 \mathrm{~W}+1 \mathrm{H}$, yaitu, what, where, when, why, dan who. Artinya intro berita belum mampu memenuhi informasi detail kepada pemirsa mengenai apa yang akan diberitakan. Misalnya unsur what (pada kalimat UNIVERSITAS VETERAN BANGUN NUSANTARA SUKOHARJO/ FAKULTAS ILMU SOSIAL POLITIK /MENGADAKAN ACARA MAKRAB. Unsur where (di mana peristiwa-nya?) yaitu pada kalimat BERTEMPATKAN DI TAWANGMANGU. Untuk unsur who (siapa pelaku/objek peristiwa) yaitu pada kalimat DIIKUTI OLEH MAHASISWA PROGDI ILMU KOMUNIKASI TAHUN ANGKATAN 2018. Sedangkan untuk unsur when (kapan peritiwa-nya?) dan unsur why (mengapa/kenapa) tidak tertulis dalam naskah. 


\section{Kepadatan (Brevity)}

Penulisan yang singkat berkaitan dengan ekonomi kata. Hal ini bertujuan agar kalimat pemberitaan yang disusun singkat. Oleh karena itu tiap kata yang ditempatkan menjadi sebuah kalimat haruslah kata yang tepat dan mudah dipahami. Hindari penggunaan kata-kata mubazir. Kata mubazir adalah kata yang bila dihilangkan dari sebuah kalimat tidak akan mengubah maknanya. Kata mubazir adalah kata yang sifatnya berlebih-lebihan, seperti bahwa, adalah, telah, untuk, dari, dan penjamakan.

\section{LEAD NEWS}

UNIVERSITAS VETERAN BANGUN NUSANTARA SUKOHARJO/

FAKULTAS ILMU SOSIAL POLITIK /MENGADAKAN ACARA

MAKRAB YANG BERTEMPATKAN DI TAWANGMANGU//

ACARA MAKRAB TERSEBUT DIIKUTI OLEH MAHASISWA PROGDI

ILMU KOMUNIKASI TAHUN ANGKATAN 2018// BERIKUT

LIPUTANNYA//

Dari kutipan naskah di atas terdapat kata mubazir seperti kata "YANG BERTEMPATKAN"dan "ACARA MAKRAB TERSEBUT" Kalimat ini menjadi kurang informatif. Tanpa menggunakan "YANG BERTEMPATKAN"dan "ACARA MAKRAB TERSEBUT" kejelasan dari naskah ini tetap tajam, apalagi ini adalah bagian intro sebelum memasuki badan narasi. Intro haruslah menjadi suatu bagian utama yang mencakup inti berita yang akan disiarkan. Sebaiknya kata "YANG BERTEMPATKAN"dan “ACARA MAKRAB TERSEBUT"dihilangkan saja karena penggunaanya mubazir dan hanya membuang waktu durasi siaran. Susunan naskah intro menjadi seperti berikut :

\section{UNIVERSITAS VETERAN BANGUN NUSANTARA SUKOHARJO/ \\ FAKULTAS ILMU SOSIAL POLITIK /MENGADAKAN ACARA MAKRAB DI TAWANGMANGU/ DIIKUTI OLEH MAHASISWA PROGDI ILMU KOMUNIKASI TAHUN ANGKATAN 2018/ BERIKUT LIPUTANNYA//}

Kata pada kalimat, FAKULTAS ILMU SOSIAL POLITIK masih kurang satu kata penghubung yaitu kata "DAN" yang seharusnya diletakkan untuk menghubungkan kata "SOSIAL POLITIK" hal ini karena berdasarkan fakta yang sebenarnya untuk penamaan institusi yang benar adalah "FAKULTAS ILMU SOSIAL DAN POLITIK". Kemudian susunan naskahnya sebaiknya ditempatkan di awal intro berita agar kesannya sesuai dengan program berita faktual bahwa berita yang ditayangkan adalah faktual, sehingga menjadi:

FAKULTAS ILMU SOSIAL DAN POLITIK/ UNIVERSITAS VETERAN

BANGUN NUSANTARA SUKOHARJO/

Kata "MAKRAB" pada kalimat "MENGADAKAN ACARA MAKRAB “ sebenarnya adalah kependekan dari kalimat "MALAM KEAKRABAN " dengan menambahkan kepajangan dan sekaligus singkatan akan memudahkan pemirsa atau penonton menangkap maksud kata “ MAKRAB” tersebut sehingga susunan kalimatnya mejadi sebagai berikut: 


\section{MENGADAKAN ACARA MALAM KEAKRABAN /MAKRAB/}

Kalimat terbalik juga terdapat pada kalimat "DIIKUTI OLEH MAHASISWA PROGDI ILMU KOMUNIKASI TAHUN ANGKATAN 2018". Kalimat "TAHUN ANGKATAN 2018" sebagiknya disusun dalam kalimat "ANGKATAN TAHUN 2018" sehingga menjadi kalimat "DIIKUTI OLEH MAHASISWA PROGDI ILMU KOMUNIKASI ANGKATAN TAHUN 2018".

Dari seluruh naskah yang tertulis pada intro berita yang digunakan oleh mahasiswa dalam karya praktikum jurnalistik televisi bila dilihat dari susunan kalimat masih banyak yang terbalik, bila dicermati dari pemilihan kata dan penggunaan kata, dalam hal ekonomi kata masih kurang cermat sehingga kata-kata mubazir masih banyak digunakan. Dari evaluasi terhadap teks intro berita yang telah dianalisis berdasarkan penerapan bahasa jurnalistik televisi sebagiknya susunan naskah berita televisi setidaknya dapat ditulis sebagai berikut:

FAKULTAS ILMU SOSIAL DAN POLITIK/ UNIVERSITAS VETERAN

BANGUN NUSANTARA SUKOHARJO/ MENGADAKAN ACARA

MALAM KEAKRABAN /MAKRAB/ DI TAWANGMANGU/ DIIKUTI

OLEH MAHASISWA PROGDI ILMU KOMUNIKASI ANGKATAN

TAHUN 2018/ BERIKUT LIPUTANNYA//

\section{Kejelasan (Clarity)}

Kalimat harus dibuat secara teratur, mulai dari pokok kalimat (subjek) sebutan (predikat), objek dan keterangan (SPOK). Usahakan supaya pokok kalimat dan sebutan letaknya berdekatan. Kalau pokok kalimat dan sebutan berjauhan letaknya akan mengacaukan perhatian.

BODY NEWS:

PEMBUKAAN MAKRAB FISIP DILAKSANAKAN PADA HARI JUMAT/

28 SEPTEMBER 2018/ DI GEDUNG D LANTAI 2/ DAN DIBUKA PUKUL

7 WAKTU INDONESIA BARAT OLEH DEKAN FISIP/ DRS. JOKO

SURYONO, M.SI.//

ACARA TERSEBUT BERLANGSUNG 3 HARI 2 MALAM/ DI VILLA

FAJAR INDAH TAWANGMANGU KANGANGANYAR//

ADA BANYAK KEGIATAN YANG DILAKSANAKAN//

KEGIATAN HARI PERTAMA/ MENGENALKAN FAKULTAS ILMU

SOSIAL DAN ILMU POLITIK/ PRODI ILMU KOMUNIKASI

UNIVERSITAS VETERAN BANGUN NUSANTARA

SUKOHARJO/KEMUDIAN HARI KEDUA DILAKSANAKANYA

KEGIATAN SENAM/OUT BON DAN MALAM HARINYA INAGURASI//

PADA HARI TERAKHIR MAKRAB DIISI JALAN SEHAT DAN

KALERAN///

Pada susunan teks naskah yang terdapat pada badan berita (body news) di atas cara narator dalam menuturkan isi berita yang memuat urut rangkaian peristiwa masih kurang cermat. Banyak kalimat yang tidak sempurna dalam hal ini adalah keberadaan subjek, predikat, objek dan keterangan. Pada teks naskah tersebut merupakan kalimat pasif. Kalimat pasif sangat tidak cocok digunakan dalam penulisan naskah berita televisi. 
Ketidakjelasan juga muncul akibat dari penggunaan kalimat yang unsur keterangan menggabungkan antara kalimat "PEMBUKAAN MAKRAB FISIP DILAKSANAKAN PADA..." dan "ACARA TERSEBUT BERLANGSUNG 3 HARI 2 MALAM ...".Hal ini memunculkan kebingungan dari pemirsa/penonton. Kalimat tersebut tiba-tiba melompat pindah keterangan tempat tanpa ada kalimat penghubung yang logis. Penulisan teks naskah badan berita tersebut masih kurang kronologis dalam menuturkan urutan kejadian sehingga pemirsa mendapatkan kesan tidak jelas terhadap isi pemberitaan yang ditayangkan. Unsur-unsur what, where, when, who, secara parsial sudah ada dan memenuhi hanya kalimat yang disusun belum mengandung maksud informasi yang enak di dengar dan ditonton. Dan unsur why dan how tidak detail dalam mengungkapkan data dan fakta. Perubahan naskah yang baik dapat dibuat seperti berikut:

BODY NEWS:

KEGIATAN MALAM KEAKABAN MAHASISWA BARU/AKRAB MARU/ PRODI ILMU KOMUNIKASI/ ANGKATAN TAHUN 2018/ FAKULTAS ILMU SOSIAL DAN ILMU POLITIK/FISIP/UNIVERSITAS VETERAN BANGUN NUSANTARA SUKOHARJO/ DILAKSANAKAN 3 HARI 2 MALAM DI VILLA FAJAR INDAH TAWANGMANGU KARANGANYAR/KEGIATAN DIMULAI TANGGAL 28 SEPTEMBER DAN BERAKHIR 30 SEPTEMBER DUA RIBU DELAPAN BELAS//

KEGIATAN DIBUKA DAN DIBERANGKATKAN SECARA RESMI OLEH DEKAN FISIP/ DRS. JOKO SURYONO, M.SI./DARI GEDUNG D LANTAI DUA FISIP UNIVET BANTARA SUKOHARJO/TEPAT PUKUL 7 WAKTU INDONESIA BARAT INI /MELIBATKAN 32 ORANG MAHASISWA SENIOR SEBAGAI PANITIA/ DAN 68 ORANG MAHASISWA BARU SEBAGAI PESERTA MAKRAB/

KEGIATAN MAKRAB MARU YANG GELAR OLEH HIMPUNAN MAHASISWA PRODI ILMU KOMUNIKASI /HIMAKOM INI/ BERTUJUAN MENJALIN KEAKRABAN ANTARA MAHASISWA BARU /DAN MAHASISWA SENIOR/ DI LINGKUNGAN PROGDI ILMU KOMUNIKASI/ ADA BANYAK KEGIATAN YANG DILAKSANAKAN SEPERTI PENGENALAN FAKULTAS/ PENGENALAN PRODI/ PENGENALAN MAHASISWA SENIOR/PENGENALAN UNIT KEGIATAN MAHASISWA/OUT BOND/MALAM INAGURASI/ SENAM SEHAT/ JALAN SEHAT/BERMAIN WARNA / KEGIATAN MAKRAB MARU INI DITUTUP DENGAN RAMAH TAMAH YANG MENGAKRAB//

KEGIATAN MAKRAB MARU DALAM RANGKA MENJALIN KEAKRABAN ANTAR MAHASISWA TERSEBUT/ DIHADIRI OLEH SELURUH DOSEN PRODI ILMU KOMUNIKASI/ KETUA DAN SEKRETARIS PRODI/ DEKAN FISIP/WAKIL DEKAN /DAN TENAGA KEPENDIDIKAN DI LINGKUNGAN FISIP// 


\section{Kesederhanaan (Simplicity)}

Penonton televisi sangat heterogen bila dilihat dari tingkat pendidikan, usia, jenis kelamin, suku dan tingkat sosial merekapun sangat berbeda (Badjuri, 2010, p. 67). Oleh karena itu bahasa jurnalistik televisi yang digunakan harus dibuat untuk ditujukan kepada yang beragam tersebut. Kalimat yang disusun haruslah sederhana, yaitu tidak mencampuradukkan kata-kata asing atau kata-kata yang kurang dikenal penonton secara umum. Kalaupun terpaksa harus menggunakan kata-kata asing karena tidak ada padanan yang tepat dalam bahasa Indonesia, berikan penjelasan secara singkat di belakangnya.

\section{LEAD NEWS}

UNIVERSITAS VETERAN BANGUN NUSANTARA SUKOHARJO/

FAKULTAS ILMU SOSIAL POLITIK /MENGADAKAN ACARA

MAKRAB YANG BERTEMPATKAN DI TAWANGMANGU//

ACARA MAKRAB TERSEBUT DIIKUTI OLEH MAHASISWA PROGDI

ILMU KOMUNIKASI TAHUN ANGKATAN 2018// BERIKUT LIPUTANNYA//

Kalimat dalam kutipan naskah intro berita di atas sebenarnya termasuk kategori cukup sederhana. Namun demikian susunan kalimatnya banyak yang terbalik sehingga dalam urutan kronologisnya masih kurang tepat meskipun secara sekilas penonton/pemirsa masih mudah memahami maksud dari informasi yang ditayangkan. Penerapan bahasa jurnalistik televisi yang cenderung ditujukan untuk pendengaran maka kalimat yang disusun semakin sederhana akan semakin menarik untuk diikuti sampai selesai.

\section{Keterpercayaan (Sincerity)}

Naskah berita televisi yang disusun haruslah berdasarkan fakta peristiwa dan fakta narasumber/saksi secara objektif. Fakta peristiwa dan fakta narasumber/saksi dapat diperkuat dengan gambar-gambar hasil shot yang menunjukkan peristiwa sebenarnya. Oleh karena itu, berita televisi harus dapat dipercaya dan memenuhi kaidah etika, undang-undang dan hukum. Sebagai jurnalis televisi harus dapat melayani kebutuhan masyarakat berdasarkan kejadian/peristiwa yang sebenarnya. Naskah berita televisi harus memuat pula data-data yang valid/dapat dipercaya dari sumber aslinya. Dalam menyajikan berita televisi, jurnalis tidak boleh berat sebelah. Jika meliput konflik atau perselisihan harus cover both sides (meliput dua sisi yang berbeda secara seimbang dan adil), tidak boleh menjadi corong satu kelompok (Badjuri, 2010, pp. 67-68). Posisi jurnalis harus independen dan bertanggungjawab.

\section{BODY NEWS:}

PEMBUKAAN MAKRAB FISIP DILAKSANAKAN PADA HARI JUMAT/

28 SEPTEMBER 2018/ DI GEDUNG D LANTAI 2/ DAN DIBUKA PUKUL 7 WAKTU INDONESIA BARAT OLEH DEKAN FISIP/ DRS. JOKO

SURYONO, M.SI.//

ACARA TERSEBUT BERLANGSUNG 3 HARI 2 MALAM/ DI VILLA

FAJAR INDAH TAWANGMANGU KANGANGANYAR//

ADA BANYAK KEGIATAN YANG DILAKSANAKAN//

KEGIATAN HARI PERTAMA/ MENGENALKAN FAKULTAS ILMU 


\begin{abstract}
SOSIAL DAN ILMU POLITIK/ PRODI ILMU KOMUNIKASI
UNIVERSITAS VETERAN BANGUN NUSANTARA

SUKOHARJO/KEMUDIAN HARI KEDUA DILAKSANAKANYA

KEGIATAN SENAM/OUT BON DAN MALAM HARINYA INAGURASI//

PADA HARI TERAKHIR MAKRAB DIISI JALAN SEHAT DAN

KALERAN///
\end{abstract}

Naskah berita televisi seperti yang dapat dilihat dari struktur naskah pada badan berita/body news tersebut sebenarnya cukup dapat dipercaya namun ada beberapa datadata yang belum lengkap sehingga penyajian informasi faktanya juga tidak lengkap. Derajat keterpercayaan dalam sebuah pemberitaan televisi sangat tergantung dariakurasi dan objektivitas informasi yang diliput oleh jurnalis televisi itu sendiri. Apabila hal ini diabaikan maka dapat berakibat tidak hanya nasib jurnalis televisi yang dipertaruhkan namun juga ijin penyiaran stasiun televisi tidak dapat diperpanjang. Berita televisi harus benar-benar dari sumber aslinya, jurnalis televisi harus benar benar meliput dari lokasi peristiwa atau kejadian.

\title{
Pengeditan Naskah Berita Televisi
}

Hasil transkrip video berita televisi yang didownload dari yotube channel dengan alamat url:

https://www.youtube.com/watch?v=601Y8

04vfj4 dengan judul berita Univet Tv - Makrab I.Kom Fisip Univet Bantara Sukoharjo sebagai berikut ini:

OPENING TELEVISI

SELAMAT PAGI PEMIRSA/ ANDA SEDANG MENYAKSIKAN UNIVET

TV/ 21 OKTOBER 2018/ BERSAMA SAYA/ FIRDA//

\section{LEAD NEWS}

UNIVERSITAS VETERAN BANGUN NUSANTARA SUKOHARJO/

FAKULTAS ILMU SOSIAL POLITIK /MENGADAKAN ACARA

MAKRAB YANG BERTEMPATKAN DI TAWANGMANGU//

ACARA MAKRAB TERSEBUT DIIKUTI OLEH MAHASISWA PROGDI

ILMU KOMUNIKASI TAHUN ANGKATAN 2018// BERIKUT LIPUTANNYA//

BODY NEWS:

PEMBUKAAN MAKRAB FISIP DILAKSANAKAN PADA HARI JUMAT/

28 SEPTEMBER 2018/ DI GEDUNG D LANTAI 2/ DAN DIBUKA PUKUL

7 WAKTU INDONESIA BARAT OLEH DEKAN FISIP/ DRS. JOKO

SURYONO, M.SI.//

ACARA TERSEBUT BERLANGSUNG 3 HARI 2 MALAM/ DI VILLA

FAJAR INDAH TAWANGMANGU KANGANGANYAR//

ADA BANYAK KEGIATAN YANG DILAKSANAKAN//

KEGIATAN HARI PERTAMA/ MENGENALKAN FAKULTAS ILMU

SOSIAL DAN ILMU POLITIK/ PRODI ILMU KOMUNIKASI 


\section{UNIVERSITAS VETERAN BANGUN NUSANTARA SUKOHARJO/KEMUDIAN HARI KEDUA DILAKSANAKANYA KEGIATAN SENAM/OUT BON DAN MALAM HARINYA INAGURASI// PADA HARI TERAKHIR MAKRAB DISI JALAN SEHAT DAN KALERAN///}

\section{CLOSSING:}

\section{INFORMASI TERSEBUT MENGAKHIRI PERJUMPAAN KITA PADA PAGI HARI INI/SAYA /FIRDA/PAMIT UNDUR DIRI/SELAMAT BERAKTIFITAS DAN SAMPAI JUMPA//I}

Hasil transkrip tersebut menunjukkan bahwa naskah berita televisi hasil liputan mahasiswa di tulis secara terburu-buru dan belum menerapkan kaidah-kaidah penggunaan bahasa jurnalistik televisi. Terlihat dari tayangan video hasil karya praktikum jurnalistik televisi naskah berita tidak diedit dengan baik, terbukti dalam pemilihan kata (diksi), penempatan kata dalam struktur kalimat dan pemenggalannya pun tidak tepat. Situasi dan kondisi ini terjadi karena kelompok tim liputan tidak meliput dari keseluruhan kegiatan makrab maru mulai dari kampus sampai di lokasi kegiatan makrab. Belum teritegrasinya antara penulis naskah berita dan kameramen dalam menyajikan informasi selengkap mungkin. Editor video belum mampu merangkai gambar peristiwa secara urut kronologis sehingga memudahkan penulis naskah menuangkan tulisan berdasarkan urutan gambar shot yang telah disusun. Pada saat anchor/pembawa berita membacakan intro berita di studio dengan format voice over semestinya disusul dengan shot-shot angel pokok peristiwa. Dan selanjutnya pada badan berita, disajiikan shot-shot berisi urutan fakta peristiwa/kejadian sebenarnya yang dapat membantu penonton/permirsa memahami maksud dan inti informasi yang ditayangkan.

Berdasarkan hasil ini, maka dapat dikatakan bahwa proses editing naskah berita televisi pada hasil karya praktikum jurnalistik televisi oleh mahasiswa belum maksimal dan memerlukan banyak referensi, bimbingan dan panduan dari praktisi profesional jurnalis televisi.

\section{KESIMPULAN DAN SARAN}

\section{Kesimpulan}

Berdasarkan hasil analisis penelitian yang dilakukan berkaitan dengan"Penerapan bahasa jurnalistik dalam penulisan naskah siaran berita hasil karya praktikum jurnalistik televisi " yang diambil dari laman https://www.voutube.com/watch?v=601Y804vfi4 dengan judul berita: Univet Tv - Makrab I.Kom Fisip Univet Bantara Sukoharjo. Analisis penelitian berdasarkan pada kriteria 5 unsur bahasa jurnalistik yaitu; ketepatan (accuracy), kepadatan (brevity), kejelasan (clarity), kesederhanaan (simplicity), dan dapat dipercaya (sincerity). Hasil penelitian menunjukkan bahwa, penulisan naskah siaran berita karya praktikum jurnalistik televisi oleh mahasiswa belum sepenuhnya menerapkan penggunaan bahasa indonesia yang baik sesuai dengan kaidah bahasa jurnalistik televisi yang memenuhi 5 kriteria unsur bahasa jurnalistik, baik itu dari pemilihan kata maupun penempatan kata dalam struktur kalimat. Sedangkan, dari sisi pengeditan naskah berita, belum ada tim khusus atau seseorang yang bertanggung jawab penuh dalam mengedit naskah berita televisi sebelum ditayangkan. 


\section{Saran}

Univet Televisi youtube channel sebagai display channel hasil karya praktikum jurnalistik televisi Prodi I.Kom FISIP Univet Bantara haruslah memberikan inovasi program yang kreatif dan mendidik didukung dengan bahasa jurnalistik yang informatif. Diharapkan kepada mahasiswa para kandidat jurnalis televisi untuk mengikuti pendidikan atau pelatihan mengenai jurnalistik dan untuk menambah referensi perlu membaca buku, yang lebih mudah mencari artikel naskah berita televisi di internet agar teknik menulis naskah berita televisi semakin baik maka kualitas para Jurnalis dapat berkembang dan profesionalitas semakin terlihat.

\section{DAFTAR PUSTAKA}

Badjuri, A. (2010). Jurnalistik Televisi. Graha Ilmu (Pertama). Yogyakarta. https://doi.org/10.1558/jsrnc.v4il.24

Baksin, A. (2006). Jurnalistik Televisi: Teori dan Praktek. (Rema Karyanti S., Ed.) (Pertama). Bandung: Simbiosa Rekatama Media.

J Suryono , P I Astuti, N T Rahayu, M. W. and H. (2019). Superlative Sign Typology of Curahan Hati - Harapan Warga Jakarta Political Advertising Video. In 2nd Workshop on Language, Literature and Society for Education (p. 2282712). https://doi.org/10.4108/eai.21-12-2018.2282712

Mahmudi, I. (2016). Bahasa sebagai Sarana Berpikir Ilmiah: Analisis Pembelajaran Bahasa Kontekstual. Universitas Negeri Jakarta, 4(1), 15-33. https://doi.org/10.21111/at-tadib.v4i1.570

Moleong, L. J. (2017). Metode Penelitian Kualitatif (Edisi Revi). Bandung: PT Remaja Rosdakarya.

Morissan. (2005). Media Penyiaran: Strategi Mengelola Radio dan Televisi. Tangerang.

Muda, D. I. (2003). Jurnalitik Televisi. Bandung: Remaja Rosdakarya.

Rahayu, A. P. (2015). Menumbuhkan Bahasa Indonesia Yang Baik dan Benar Dalam Pendidikan dan Pengajaran. Jurnal Paradigma, 2(1), 1-15.

Sugiyono. (2017). Metode Penelitian Kualitatif. Metode Penelitian (Edisi keti). Bandung: Penerbit Alfabeta.

Usman, K. (2009). Television News Reporting \& Writing, Panduan Praktis Menjadi Jurnalis Televisi (Pertama). Bogor: Penerbit Ghalia Indonesia.

Wiratno, T., \& Santosa, R. (2014). Bahasa, Fungsi Bahasa, dan Konteks Sosial. Modul Pengantar Linguistik Umum, 1-19.

Zaenuddin, H. M. (2007). The journalist. Jakarta: Prestasi Pustaka. 